\title{
Role and efficacy of vaginal dinoprostone gel (PGE2) plus vaginal misoprostol (PGE1) in second trimester termination of pregnancy
}

\author{
Abhijeet Kumar ${ }^{1 *}$, Raju Agarwal ${ }^{2}$ \\ ${ }^{1}$ Department of Obstetrics and Gynecology, Military Hospital Ramgarh Cantt, Ramgarh, Jharkhand, India \\ ${ }^{2}$ Department of Obstetrics and Gynecology, Command Hospital Lucknow, Lucknow, Uttar Pradesh, India
}

Received: 31 January 2018

Accepted: 05 February 2018

*Correspondence:

Dr. Abhijeet Kumar,

E-mail: xyzabhi@yahoo.com

Copyright: ( $\odot$ the author(s), publisher and licensee Medip Academy. This is an open-access article distributed under the terms of the Creative Commons Attribution Non-Commercial License, which permits unrestricted non-commercial use, distribution, and reproduction in any medium, provided the original work is properly cited.

\section{ABSTRACT}

Background: The addition of dinoprostone gel (PGE2) to standard regimen of second trimester abortion using vaginal misoprostol (PGE1) reduces failure rate and decrease induction abortion time interval. We evaluated the role and efficacy of vaginal dinoprostone gel with vaginal misoprostol in women undergoing second trimester abortion. Objective of present study was to assess the safety and effectiveness of vaginal dinoprostone gel plus vaginal misoprostol for second trimester termination of pregnancy.

Methods: This study was a prospective cohort involving 100 women with 12-20 weeks gestation requesting termination of pregnancy. In study group $0.5 \mathrm{mg}$ dinoprostone gel applied vaginally followed by $400 \mu \mathrm{g}$ misoprostol every four hourly (max 3 doses) after six hours of dinoprostone gel application. The mean age of the women study was 27.2 years and mean gestational age was 18.9 weeks. The primary effectiveness of the study was the efficacy of the treatment to terminate pregnancy at $20 \mathrm{hrs}$. Secondary outcomes were induction abortion interval, failure rate, side effects. statistical analysis of study was carried out using chi square test.

Results: At 20 hours, the complete abortion rate was 100\%. Within 16 hours $98 \%$ women aborted without any significant side effects. Mean induction abortion interval was 14.56 hours.

Conclusions: Combination of vaginal dinoprostone gel (PGE2) plus misoprostol (PGE1) is effective, safe and alternate method for second trimester pregnancy termination with. In this protocol induction to abortion interval time is less as compared to other methods of second trimester pregnancy termination.

Keywords: Dinoprostone gel, Misoprostol, PGE1, PGE2, Prostaglandin, Second trimester termination of pregnancy

\section{INTRODUCTION}

Second trimester termination contributes approximately $10 \%$ to $20 \%$ of all induced abortions cases and about $65 \%$ to $70 \%$ of all fatal complications are related to induced abortions. Various agents are used to ripen the cervix and stimulate uterine contractions and induce abortion after 12 weeks, but available data regarding their safety and effectiveness are limited. ${ }^{1,2}$ Various agents include hypertonic saline, or hyperosmolar urea, injected intra-amniotically; ethacridine lactate administered intra- or extra-amniotically; prostaglandin analogues administered parenterally or intra- or extra-amniotically; and oxytocin injected intravenously or intramuscularly. These methods and routes of administration, however, are invasive and likely to be less safe, and the time to complete abortion is longer when compared to the use of methods such as misoprostol alone, combined dinoprostone and misoprostol combined mifepristone and misoprostol..$^{2-5}$ Second trimester abortion also includes surgical procedure, but it can result in complications like uterine perforation, cervical incompetence, uterine 
synechiae and even maternal mortality. The intent of this study is to study the effectiveness and safety of intravaginal dinoprostone gel plus misoprostol in second trimester pregnancy termination. Among prostaglandins, prostaglandin E1 and E2 analogues have been tried in different doses and by various routes for second trimester abortion. ${ }^{6}$ Misoprostol, a synthetic 15-deoxy16-hydroxy 16-methyl analogue of PGE1 being much cheaper, safe and capable of being easily stored at room temperature has been tried by both oral and vaginal routes in different dosage regimens with varying degrees of success. ${ }^{7}$

Oral misoprostol is associated with faster achievement of peak levels, but the effect lasts for less time and it is also associated with more side effects. ${ }^{8}$ However vaginal route is associated with slower peak level achievement, but the effect lasts longer with fewer side effects. ${ }^{9}$ Prostaglandin E2 gel was used for cervical ripening before induction of labor in patient having low bishop score. Studies and result indicate that local prostaglandin E2 is superior to placebo or no therapy in enhancing cervical effacement and dilation, reducing initial induction failures, shortening the induction-delivery interval, decreasing oxytocin use. ${ }^{10-12}$ On the premise of additive effect of both PGE1 and PGE2 for cervical dilation, and on labour induction. Each having slightly different mechanism of action adding to better clinical efficacy and safety. ${ }^{13-16}$

\section{METHODS}

$\mathrm{T}$ Prospective non randomised open label study was carried out in military hospital over period of two year (2015-2016). 116 healthy women, between age 18 to 38 years, with 12-20 weeks of pregnancy, requesting second trimester termination of pregnancy, were included in this study. The indications for termination were as per indication of MTP Act. Gestational age was estimated as per guidelines issued by ACOG. informed consent of all pregnant women was taken before enrolment and the study was approved by the ethical committee of the institution. Exclusion criteria were women with multiple pregnancy, baseline hemoglobin less than $8 \mathrm{gm} / \mathrm{dl}$, previous cesarean section, maternal local or systemic infection and any degree of cervical dilatation. We also excluded patients who had any pulmonary, hepatic, renal or cardiovascular disease. All the women received initially $0.5 \mathrm{mg}$ dinoprostone gel (PGE2) vaginally followed by $400 \mu \mathrm{g}$ misoprostol every four hourly (max 3 doses) after six hours of dinoprostone gel (PGE2) application.

Women's vital signs were monitored every two hours and the process of abortion was assessed by vaginal examination four hourly during each dose administration. If any women failed to abort after three doses of misoprostol (400 mcg four hourly), the same protocol was repeated 24 hours later of first dose of dinoprostone gel (PGE2). After the abortion was complete the products of conception were checked for its completeness and induction-abortion interval was calculated and noted. If the abortion was incomplete, it was completed using oxytocin drip. After abortion patients were observed for 24 hours before discharge and failure of abortion was considered when a woman failed to abort within 48 hours of the start of treatment. Other method for termination of pregnancy were undertaken for failed cases. Information about side effects was taken from each woman including nausea, vomiting, diarrhoea, fever and abdominal pain. On discharge they were asked to come for follow up after a week or earlier if need arises. On follow up, a pelvic examination was performed an all the women and an inquiry made of any abnormal bleeding or delayed side effects.

\section{Trial outcomes}

The primary outcomes the study was the effectiveness of the treatment to terminate pregnancy at $20 \mathrm{hrs}$. The secondary outcome measures were induction-abortion interval (hours), number of failure cases, need for surgical evacuation in incomplete cases and side effects. The in-duction-abortion interval was defined as the interval between the time of administration of the first dose of dinoprostone gel (PGE1) and the time when the fetus was aborted.

\section{Statistical analysis}

The statistical analysis was performed by using Chisquare analysis were done to assess the significance of variables and p-value less than 0.05 was considered as statistically significant value.

\section{RESULTS}

Table 1 shows age distribution in our study. Age ranged from 18 to 40 years. Maximum number $(52 / 100,52 \%)$ of women was in 26-30 year age group and mean age was 27.2 years. Seventy four women $(74 \%)$ had gravidity of two or more and the mean gravidity was 2.6.

Table 1: Age distribution $(n=100)$.

\begin{tabular}{|ll|}
\hline Age (years) & Number $(\%)$ \\
$\leq 20$ & $4(4 \%)$ \\
\hline $21-25$ & $27(27 \%)$ \\
\hline $26-30$ & $52(52 \%)$ \\
\hline $31-35$ & $15(15 \%)$ \\
\hline$>35$ & $2(2 \%)$ \\
\hline Mean age 27.2 years & \\
\hline
\end{tabular}

Table 2: Period of gestation $(n=100)$.

\begin{tabular}{|lc|}
\hline Weeks & Number $(\%)$ \\
\hline $12-14$ & $10(10 \%)$ \\
\hline $14-16$ & $18(18 \%)$ \\
$16-18$ & $34(34 \%)$ \\
\hline $18-20$ & $38(38 \%)$ \\
\hline \multicolumn{2}{|l|}{ Mean gestational age was 18.9 weeks } \\
\hline
\end{tabular}


The two common indications were congenital anomaly and intrauterine fetal death.

Table 3 shows the relationship of induction abortion interval to the gestational age. Most of the women (72\%) aborted between 12 and 14 hours, while $98 \%$ aborted within 16 hours and $96.6 \%$. The mean induction abortion interval was $12.58 \pm 1.02$ (SD) hours. There is no relationship be-tween gestational age and induction abortion interval $(\mathrm{P}>0.5)$. Except minor side effects like nausea, vomiting and diarrhoea, no major drug related side effects were observed in the study population. The average total dose of misoprostol in our study was 800 microgram.

Table 3: Induction abortion interval.

\begin{tabular}{|c|c|c|c|c|c|c|c|c|}
\hline Weeks & 4-6 hrs & 6-8 hrs & 8-10 hrs & $10-12 \mathrm{hrs}$ & 12-14 hrs & $14-16 \mathrm{hrs}$ & $>16 \mathrm{hrs}$ & Total \\
\hline $12-16$ & - & - & 2 & 12 & 12 & 2 & - & 28 \\
\hline $16-20$ & - & - & 4 & 4 & 60 & 2 & 2 & 72 \\
\hline
\end{tabular}

There was no case of failure in this regime as per method of this study. Also, there was no need for any surgical evacuation as there was no case of retained product of conception. Side effect like nausea, vomiting, pain abdomen was less as compared to other methods of termination however statistically insignificant.

\section{DISCUSSION}

Abortions during second trimester represent only $10 \%$ $15 \%$ of all induced abortions but it leads to $65 \%$ to $70 \%$ of all maternal morbidity, $50 \%$ of maternal mortality is accounted for this practice. ${ }^{1,2}$ Hence it is imperative to develop effective and safe method for second trimester abortions to decrease maternal morbidity and mortality. In the past misoprostol, in combination with other agents such as mifepristone, oxytocin, PGF2A, PGE2 has been investigated for second trimester medical abortion. ${ }^{3-5}$ Different studies have shown that pre-treatment with dinoprostone gel (PGE2) resulted in a shorter induction abortion interval com-pared with regimens without dinoprostone gel. ${ }^{6}$ Abortifacient properties of misoprostol for termination in the second trimester have been reported in the medical literature since $1993 .^{7}$ Several numbers of studies have demonstrated that it is safe and efficient drug for achieving fetal expulsion. Moreover, it is inexpensive and can be stored in room temperature. ${ }^{8}$ Due to lack of evidences from well controlled randomized studies, consensus is yet to be reached regarding optimal dose, route and time interval of misoprostol administration for induction of medical abortion. Oral route is easy to administer, but there is increased incidence of gastrointestinal side effects along with increased induction-abortion interval. Vaginal route had been found to be more promising than oral route probably due to an accumulating plasma level with fewer gastrointestinal side effects. ${ }^{9-11}$ In such a context, we found this regime of vaginal administration of $0.5 \mathrm{mg}$ of dinoprostone gel (PGE1) followed by $400 \mu \mathrm{g}$ misoprostol 4 hourly very effective for second trimester pregnancy termination. Mean induction abortion interval in our study was $12.58 \pm 1.02$ hours which is comparable to 12 16 hours in other studies and with better induction to interval time. ${ }^{12-15}$

Thus, vaginal dinoprostone gel with misoprostol is found to be an efficient and time saving drug for second trimester pregnancy termination. These drugs are easily available in any obstetric unit. Drug related side effects and procedure related complications were very low, which is comparable to different studies. ${ }^{9,13,15}$ In present prospective study $98 \%$ women aborted within 16 hours, which is comparable to about ninety percent as reported by other studies. ${ }^{13-15}$

\section{CONCLUSION}

Vaginal dinoprostone (PGE2) gel plus misoprostol (PGE1) is a safe and effective protocol with less induction to abortion interval method for second trimester pregnancy termination. Further studies to compare its safety and efficacy with other methods of termination of mid trimester pregnancy can be carried out.

Funding: No funding sources

Conflict of interest: None declared

Ethical approval: The study was approved by the Institutional Ethics Committee

\section{REFERENCES}

1. World Health Organization. Medical methods for termination of pregnancy: report of a WHO Scientific Group. World Health Organization. Geneva; 1997.

2. Tietza, C. Second-Trimester Abortion: A Global View. In: Berger GS, Berger WE, Keith LG, Eds., John Wright, Boston;1981:1-11.

3. Gómez PD, Wing DA. Misoprostol for termination of pregnancy with intrauterine fetal demise in the second and third trimester of pregnancy-a systematic review. Contraception. 2009 Apr;79(4):259-271. 
4. El-Refaey H, Templeton A. Pregnancy: Induction of abortion in the second trimester by a combination of misoprostol and mifepristone: a randomized comparison between two misoprostol regimens. Human Reprod. 1995 Feb;10(2):475-8.

5. Ho PC, Chan YF, Lau W. Misoprostol is as effective as gemeprost in termination of second trimester pregnancy when combined with mifepristone: a randomised comparative trial. Contraception. 1996 May 1;53(5):281-3.

6. Wong KS, Ngai CS, Yeo EL, Tang LC, Ho PC. A comparison of two regimens of intravaginal misoprostol for termination of second trimester pregnancy: a randomized comparative trial. Human Reprod. 2000 Mar;15(3):709-12.

7. Zieman M, Fong SK, Benowitz NL, Banskter D, Darney PD. Absorption kinetics of misoprostol with oral or vaginal administration. Obstet Gynecol. 1997 Jul;90(1):88-92.

8. Tang OS, Schweer H, Seyberth HW, Lee SW, Ho PC. Pharmacokinetics of different routes of administration of misoprostol. Human Reprod. 2002 Feb 1;17(2):332-6.

9. Meckstroth KR, Whitaker AK, Bertisch S, Goldberg AB, Darney PD. Misoprostol administered by epithelial routes: drug absorption and uterine response. Obstet Gynecol. 2006 Sep;108(3, Part 1):582-90.

10. Ho PC, Ngai SW, Liu KL, Wong GC, Lee SW. Vaginal misoprostol compared with oral misoprostol in termination of second-trimester pregnancy. Obstet Gynecol. 1997 Nov;90(5):735-8.
11. Ngai SW, Tang OS, Ho PC. Prostaglandins for induction of second-trimester termination and intrauterine death. Best Pract Res Clin Obstet Gynecol. 2003 Oct;17(5):765-75.

12. Tang OS, Lau WN, Chan CC, Ho PC. A prospective randomised comparison of sublingual and vaginal misoprostol in second trimester termination of pregnancy. BJOG. 2004 Sep 1;111(9):1001-5.

13. Bhattacharjee N, Saha SP, Ghoshroy SC, Bhowmik $\mathrm{S}$, Barui G. A randomised comparative study on sublingual versus vaginal administration of misoprostol for termination of pregnancy between 13 to 20 weeks. Australian New Zealand J Obstet Gynaecol. 2008 Apr;48(2):165-71.

14. von Hertzen H, Piaggio G, Wojdyla D, Huong NT, Marions L, Okoev $\mathrm{G}$ et al. Comparison of vaginal and sublingual misoprostol for second trimester abortion: randomized controlled equivalence trial. Human Reprod. 2008 Sep;24(1):106-12.

15. Ganguly RP, Saha SP, Mukhopadhyay S, Bhattacharjee N, Bhattacharyya SK, Patra KK. A comparative study on sublingual versus oral and vaginal administration of misoprostol for late first and early second trimester abortion. J Indian Med Assoc. 2010 May;108(5):283-4.

Cite this article as: Kumar A, Agarwal R. Role and efficacy of vaginal dinoprostone gel (PGE2) plus vaginal misoprostol (PGE1) in second trimester termination of pregnancy. Int J Reprod Contracept Obstet Gynecol 2018;7:888-91. 